\title{
The role of water education in achieving the Millennium Development Goals?
}

\author{
Richard A. Meganck
}

Published online: 19 February 2010

(C) Springer Science+Business Media B.V. 2010

Like it or not, the Millennium Development Goals (MDGs) adopted by the Member States of the United Nations in 2000 have dominated the agendas of development agencies and organizations-inside the $\mathrm{UN}$ to be sure, but also in many bilateral donors, development banks, and multilateral aid organizations in the NGO sector. And in typical fashion and rapid succession the international community developed new programs in response-with the aim of both catalyzing the process and its needed funding, as well as tracking its progress including: the Millennium Ecosystem Assessment, the Millennium Project, the Millennium Challenge Account, the Millennium Promise, etc.

Initially, it was felt that meeting the eight MDGs would cost some \$40-60 billion each year in additional development assistance. What those figures did not include however was the needed boost in R\&D that would have to support the flow of aid if practical, dare I mention sustainable, solutions would be forthcoming. Subsequently, and not that long after the MDGs were adopted, the combined R\&D and investment figure was adjusted upward to $\$ 100$ billion annually. And the truth is that even that figure has been called into question as little more than a 'shot in the dark.'

R. A. Meganck ( $\square)$

UNESCO-IHE Institute for Water Education, Delft,

The Netherlands

e-mail: rameganck@gmail.com
Much has also been written about the starts and stops of the MDG process, but as we approach the two-thirds mark since their adoption and the 2015 date by which time we were supposed to have met the goals, it may be worthwhile to reinforce one aspect of the process that seems fundamental regardless of the funding or timing involved. And let me be clear that I can really only address two of the 18 MDG targets in any detail: those of (1) reducing by half the number of people without access to sufficient quantities of safe drinking water from the 2000 estimate of 1.2 billion, and (2) reducing by half the number of people without access to sanitation from the estimate at that time of 2.2 billion people.

Investment in education at all levels, but particularly post-graduate education, to develop the next generation of water and environmental managers and scientists is seriously lagging behind what is needed if the MDGs are to be met. This reality is not exclusively a developing country issue. Parts of Scandinavia and Western Europe will loose upwards of $30 \%$ of their environmental professionals in the next 5-10 years as the post-60s generation of scientists and academics retire in rather large waves. But the problem is most critical in the South. UNESCO-IHE Institute for Water Education undertook a preliminary assessment of the situation in 2007 which will be validated at a higher degree of confidence this year, but our initial findings are rather startling. A $300 \%$ increase in water technicians, engineers, managers, and scientists is needed in Africa if the investments being made in the 
water sector are to have any chance of being sustainable. Asia needs about a $200 \%$ increase and Latin America about a 50\% increase in the number of water and environmental specialists. It must be understood however, that to meet these goals we are not only talking about money and post-graduate education but education at all levels-both formal and informal and including vocational and life-long education offered through hands-on field experience, community colleges, mentoring, volunteer and community service programmes, among many other mechanisms. In short, we need to foment a 'water consciousness' as profound as that developed around the anti-littering or wearing a seat belt campaigns. Primary and secondary school curricula must begin to include both natural and social science aspects focused on water and its importance to development.

My main point is that investments in pipes and pumps, while obviously important, will not address the underlying principles of the MDGs without sufficient numbers of people to manage these investments overtime.

So what can we do to begin to address this crises? My seven-point point plan will not solve all the related issues, but it should open a dialogue and form the basis for a series of trials or pilot endeavors. First, we academics have to fully accept the reality that unless we work in pro-active partnerships with education institutions in the South sharing professors, courses, credits, research projects, etc. we will fail; we will ALL fail. Secondly, we must understand and accept applied research as being equal in importance to empirical research. Third, support thesis and other research in the South and joint South-South research efforts, including sharing our data in order to allow for meaningful comparisons and setting realistic goals. Fourth, we in the North have to get over the idea that we must have the lead role in research projects. To that end, funding must actually be shared and I am not simply speaking of in-kind support, but of actual cash flowing to the South in support of pilot endeavors, and other assistance that while not true research will have an impact on the quality of life in the short and medium term. Fifth, we have a responsibility to encourage our colleagues in the South to write and publish in the most prestigious of outlets, and at times as the lead author. This also includes encouraging our graduate students to take the opportunity to publish the results of their thesis research in both referred journals as well as practitioner/technician-outlets oriented to those people actually doing the work in the field. Sixth, we must somehow find a way to imbue the aid providers with the knowledge that providing fellowships is as tangible an investment as installing a latrine or a standpipe. Young graduates have a career trajectory of 25-30 years, fully qualifying us to discard the term 'donation' and replace it with the term 'investment.' And lastly, scientists must form a binding alliance with the NGO and informal education sector to ensure that the entire range of 'specialists' is trained. Not everyone needs a $\mathrm{PhD}$ to have an impact in their village.

While UNESCO-IHE has been training water sector scientists, engineers and managers at the post graduate level since 1957, it is only part of the answer as has been noted above. Education at all levels concerning water and its management will inevitably lead to a higher quality life for all citizens. Finally, I must note the absolute importance of developing and maintaining networks of people interested in water. One never knows what bit of information will serve as a catalyst for a student to begin a science project that will lead to an important discovery or a future scientist. These types of partnerships are paying everincreasing dividends to villages, cities and countries all over the world. Some might say that our combined contribution has made a difference in the quality of life. I would add that it has also made development assistance more viable and sustainable. At least the risk of failure has been reduced, if not the chance for success increased. 